\title{
Importance of Smoking in Pulmonary Involvement of Rheumatoid Arthritis
}

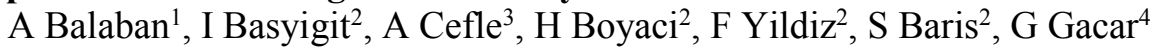

\begin{abstract}
Objectives: The aim of this study was to evaluate the effect of smoking on disease activity and pulmonary involvement in patients with rheumatoid arthritis (RA).

Methods: Bronchoscopy with bronchoalveolar lavage (BAL) was performed in patients who were diagnosed as rheumatoid arthritis with pulmonary involvement. Rheumatoid factor (RF), anti-cyclic citrullinated peptide (anti-CCP), C-reactive protein (CRP), and erythrocyte sedimentation rates were recorded to evaluate disease activity. BAL findings were compared between smoker and non-smoker patients with RA and age-matched healthy controls.
\end{abstract}

Results: A total of 34 patients were included in the study. The age of onset for RA found to be lower (45.35 \pm 8.44 vs $50.82 \pm 13.02, \mathrm{p}=0.005)$ and duration of disease found to be shorter $(6.67 \pm 5.67 v s$ $11.26 \pm 9.09, \mathrm{p}=0.005)$ in the smoker group. There was a significant correlation between smoking history and positivity of RF and anti-CCP. Alveolar macrophages in the BAL fluid was higher in patients with RA, whereas neutrophil count was higher in healthy controls. No significant difference was found between smoker and non-smoker patients in terms of BAL fluid findings.

Conclusion: Smoking might be associated with markers of disease activity, younger age of onset and pulmonary involvement within shorter disease duration in rheumatoid arthritis.

Keywords: Anti-CCP, bronchoalveolar lavage, rheumatoid arthritis, smoking, inflammation

From: ${ }^{1}$ Department of Pulmonary Diseases, Evliya Celebi Hospital, Kutahya, ${ }^{2}$ Department of Pulmonary Diseases, Kocaeli University School of Medicine, Kocaeli, ${ }^{3}$ Department of Rheumatology, Kocaeli University School of Medicine, Kocaeli, ${ }^{4}$ Stem Cell and Gene Therapy Research Center, Kocaeli University, Kocaeli, Turkey.

Correspondence: Dr A Balaban, Department of Pulmonary Diseases, Evliya Celebi Hospital, Kutahya, Turkey. E-mail: dr.azembatbalaban@hotmail.com

*The abstract of this is study presented as an oral presantation at the Annual Congress of Turkish Respiratory Society on .... in Turkey. 


\section{INTRODUCTION}

Rheumatoid arthritis (RA) is a chronic, multi-systemic disease of unknown origin. The most characteristic feature of RA is inflammatory synovitis which is usually distributed symmetrically in the peripheral joints (1). It is the most common inflammatory arthritis, with a prevalence of $1 \%$ in the general population (2). Although the exact causes of RA are unknown, several genetic and environmental factors are thought to play a role as etiological agents. Smoking has been reported as an important risk factor in the development of the disease. Furthermore, both duration and intensity of smoking is believed to be related to the severity of the disease (3).

The extra-articular manifestations of RA involve pulmonary, pleural and pericardial lesions $(4,5)$. Rheumatoid nodules, Caplan's syndrome, diffuse interstitial disease, vasculitis, follicular bronchiolitis, bronchiolitis obliterans (BO), and organizing pneumonia (OP) can be seen in RA as pulmonary manifestations (6).

High-resolution computed tomography (HRCT) has been demonstrated to be more sensitive in the diagnosis of interstitial lung disease (ILD) associated with RA and other connective tissue disorders, as compared to chest X-ray. The incidence of lesions detected by HRCT in RA patients with lung involvement is reported to vary between $49-81 \%(5,7)$. The diagnostic value of posteroanterior (PA) chest X-ray alone for the evaluation of lung involvement is reported to be $1.6 \%$ in patients with RA (8).

Bronchoalveolar lavage has been proved to be useful in understanding the underlying pathophysiology and inflammatory process of ILD. Also, several differences between cellular and humoral components in BAL fluid have been demonstrated in ILD (9).

It is not clearly defined why lung involvement is more prominent in some patients while the disease is limited to the joints in others. Since it is believed that smoking plays an 
important role in both etiology and progression of the disease, the influence of smoking in pulmonary involvement also needs to be clearly demonstrated.

The aim of this study is to assess the effects of smoking on markers of disease activity, pulmonary functions and alveolar inflammation parameters in patients with RA.

\section{MATERIAL AND METHOD}

The local ethical committee approved the study and the written informed consent of all participants were obtained. RA patients with pulmonary involvement shown by clinical, functional, and/or radiographic findings were included in the study. Patients were diagnosed according to the American Rheumatism Association criteria. Patients who had another collagen vascular disease; respiratory system disease such as chronic obstructive pulmonary disease, asthma or, active tuberculosis; history of malignancy; or a history of a respiratory tract infection within the past 4 weeks, were excluded from the study.

All patients completed a questionnaire to reveal demographic characteristics, smoking history, symptoms, disease duration, and current medication. Complete blood count and routine biochemical profile study were performed along with the evaluation of $\mathrm{C}$ - reactive protein (CRP), rheumatoid factor (RF), and anti- cyclic citrullinated peptide (anti-CCP) levels. RF titers over $20 \mathrm{IU} / \mathrm{ml}$ and anti-CCP titers over $5 \mathrm{RU} / \mathrm{ml}$ were considered seropositive. IMMAGE 800 Immunochemistry System (Beckman Coulter ${ }^{\circledR}$, CA, USA) device was used to measure serum CRP and RF levels by nephelometric method. Anti-CCP level was studied with DSX microElisa (Dynex $\operatorname{Tech}^{\circledR}$, Czechoslovakia) device by ELISA method. 
Pulmonary function tests including total lung capacity and diffusion capacity were applied. Chest X-ray, computed tomography (CT) of thorax and bronchoscopy were performed in all study population in order to compare smoker and non-smoker patients with RA.

Control group (n: 5) consisted of age-matched patients who underwent diagnostic bronchoscopy for conditions other than inflammatory lung disease and accepted the performance of bronchoalveolar lavage.

Bronchoscopy was performed by using a video bronchoscope (Fujinon ${ }^{\circledR}$, New Jersey, USA) in patients who gave informed consent to the procedure. BAL fluid was aspirated from the medial segment of the right middle lobe using an Olympus ${ }^{\circledR}$ (Hamburg, Germany) brand catheter. In total, $100 \mathrm{cc}$ of sterile saline was divided into five portions using sterile injectors of $20 \mathrm{cc}$ and each was given to the right medial lobe via catheter at a rate of $5 \mathrm{~mm} / \mathrm{s}$. The procedure deemed successful when at least $40 \%$ of the injected saline was re-aspirated. The collected BAL fluid was studied by flow cytometric examination.

Parameters such as forced expiratory volume in one second $\left(\mathrm{FEV}_{1}\right)$, forced vital capacity (FVC), $\mathrm{FEV}_{1} / \mathrm{FVC}$, forced mid-expiratory flow rate (FEF25-75), total lung capacity (TLC), carbon monoxide diffusion capacity (DLCO) were measured using ZAN $^{\circledR}$ body plethysmograph (Germany). Spirometric measurements were expressed as the percent of the predicted value based on gender, age, and height.

The results were evaluated as follows:

Restrictive disorder: $\mathrm{FVC}<80 \%, \mathrm{FEV}_{1} / \mathrm{FVC}>70 \%$, TLC $<80 \%$

Obstructive disorder: $\mathrm{FEV}_{1} / \mathrm{FVC}<70 \%$

Normal: FVC between $80-100 \%$, FEV $_{1}>80 \%$, FEF25-75> 60\%, TLC between $80-120 \%$ 
Chest X-ray was performed using $300 \mathrm{~mA}$ and $110 \mathrm{kVp}$ with conventional posteroanterior position. Thoracic CT was studied in the supine position using Toshiba Aquilion ${ }^{\circledR}$ (Tokyo, Japan) tomography device and slices of $0.5 \mathrm{~mm}$ thickness were applied from lung apex to the base of lung, with $0.3 \mathrm{~mm}$ table movement in a single breath-hold. The pathologic pulmonary lesions were categorized as nodules (solitary, multiple), interstitial lung involvement, air trapping, pleural effusion, mediastinal lymphadenopathy, cavity and bronchiectasis, according to the chest X-ray and CT findings. Ground-glass density, honeycomb appearance, reticular and reticulonodular opacities were evaluated as interstitial lung involvement.

\section{Statistics}

SPSS (Statistical Package for Social Sciences) 13.0 package program was used for statistical analysis of the data. Descriptive analysis (mean, standard deviation) was used to assess the demographic characteristics of both groups. Student's t-test was used for the comparison of quantitative data. Significance between groups was evaluated using Mann-Whitney U test, whereas chi-squared test was used to compare the qualitative data. $\mathrm{p}<0.05$ was recognized as statistically significant with a confidence interval of $95 \%$.

\section{RESULTS}

A total of 34 patients, 24 female $(70.5 \%)$ and 10 male $(29.5 \%)$, were included in this study. All the patients were under RA therapy consisted of either a single agent or a combination including methylprednisolone, methotrexate, leflunomide, salazopyrin, etanercept and adalimumab. The mean age of non-smoker RA patients was significantly higher than that of the smokers $(62.1 \pm 8.3$ vs $52.05 \pm 9.4, \mathrm{p}=0.003)$. The number of female patients was 
significantly higher in the non-smoker group $(\mathrm{p}=0.02)$. The age of onset for RA found to be lower $(45.35 \pm 8.44$ vs $50.82 \pm 13.02, \mathrm{p}=0.005)$ and duration of disease found to be shorter $(6.67 \pm 5.67$ vs $11.26 \pm 9.09, \mathrm{p}=0.005)$ in the smoker group compared to the non-smokers. The smoking history was $22.2 \pm 14.9$ pack-years (median 25 pack-years) for active smokers. Patient demographics are summarized in Table 1.

Table 1: Patient demographics

\begin{tabular}{cccc}
\hline & Smoker & Non-smoker & p \\
\hline Age (year) & $52.05 \pm 9.48$ & $62.11 \pm 8.33$ & $0.003^{*}$ \\
Gender & $8 / 9$ & $2 / 15$ & $0.02^{*}$ \\
(Male/Female) & & & \\
Age of RA onset & $45.35 \pm 8.44$ & $50.82 \pm 13.02$ & $0.005^{*}$ \\
(year) & & & \\
Duration of RA (year) & $6.67 \pm 5.67$ & $11.26 \pm 9.09$ & $0.005^{*}$ \\
FVC (\%) & $89.64 \pm 25.95$ & $83.17 \pm 18.64$ & 0.39 \\
FEV1 (\%) & $85.00 \pm 24.36$ & $84.47 \pm 19.82$ & 1.00 \\
FEV1/FVC (\%) & $116.1 \pm 28.1$ & $121.8 \pm 19.62$ & 0.44 \\
DLCO (\%) & $64.31 \pm 11.05$ & $73.76 \pm 34.32$ & 0.41 \\
TLC (\%) & $85.47 \pm 19.40$ & $82.52 \pm 31.17$ & 0.23 \\
\hline
\end{tabular}

There were 23 patients with positive RF test, while 15 of 23 patients were smokers and 8 of them were non-smokers. There was a statistically significant difference between smoking history and positive RF test $(p=0.02)$. Similarly, positive anti-CCP results was significantly higher in the smoker group than in the non-smoker group $(\mathrm{p}=0.04)$ (Table 2). 
Table 2: Relation of smoking with RF and anti-CCP titers

\begin{tabular}{lllll}
\hline & $\begin{array}{l}\text { Non-smoker } \\
(\mathbf{n = 8})\end{array}$ & $\begin{array}{l}\text { Ex-smoker } \\
(\mathbf{n = 7})\end{array}$ & $\begin{array}{l}\text { Active } \\
\text { smoker } \\
(\mathbf{n = 8})\end{array}$ & $\mathbf{p}$ \\
\hline $\begin{array}{l}\text { RF-titer (IU/ml) } \\
\text { (median) }\end{array}$ & 20.0 & 59.0 & 133.5 & $0.02 *$ \\
$\begin{array}{l}\text { Anti-CCP-titer (RU/ml) } \\
\text { (median) }\end{array}$ & 5.5 & 53.0 & 91.7 & $0.04 *$ \\
\hline
\end{tabular}

There was no significant difference in PFT values between the groups. Normal PFT result was found in 6 patients. The most frequent abnormality was restrictive defect which was more common in non-smokers, while over inflation and obstruction were more common in smokers. The decrease in diffusion capacity was observed in16 patients in the smoker group and in 11 patients in the non-smoker group $(\mathrm{p}=0.44)$. Obstructive pattern was found in 2 patients among smokers (11.7\%), however, no significant correlation was found with smoking history (Table 3).

Table 3: Distribution of cases relative to findings of pulmonary function test

\begin{tabular}{|c|c|c|c|c|}
\hline & \multicolumn{2}{|c|}{$\begin{array}{c}\text { Smoker } \\
(n=17)\end{array}$} & \multicolumn{2}{|c|}{$\begin{array}{c}\text { Non-smoker } \\
(n=17)\end{array}$} \\
\hline & $\mathbf{n}$ & $\%$ & $\mathbf{n}$ & $\%$ \\
\hline Normal & 1 & 5.9 & 5 & 29.4 \\
\hline Decreased DLCO* & 16 & 100 & 11 & 64.7 \\
\hline Restriction & 4 & 23.5 & 7 & 41.1 \\
\hline Over inflation & 3 & 18.7 & 1 & 5.9 \\
\hline Obstruction & 2 & 11.7 & \multicolumn{2}{|c|}{0} \\
\hline Mixed type disorder & 1 & 5.8 & \multicolumn{2}{|c|}{0} \\
\hline
\end{tabular}

*One patient did not cooperate in DLCO testing 
The distribution of radiographic findings was found to be similar between smokers and non-smokers (Table 4). Interstitial lung involvement and mediastinal lymphadenopathy were more common in non-smokers, while air trapping was more common in smokers. However, this difference did not reach a statistically significant level. Interstitial opacities were more frequent in females than in males (13 of 24 female patients [54\%] vs. 3 of 10 male patients $[30 \%], \mathrm{p}=0.036)$

Table 4: Distribution of cases relative to radiographic findings

\begin{tabular}{|c|c|c|c|c|c|c|c|}
\hline & $\begin{array}{c}\text { Nodule } \\
\text { n } \\
(\%)\end{array}$ & $\begin{array}{c}\text { Fluid } \\
\text { n } \\
(\%)\end{array}$ & $\begin{array}{c}\text { Interstitial } \\
\text { density } \\
\text { n } \quad(\%)\end{array}$ & $\begin{array}{c}\text { Overinflation } \\
\text { n } \\
(\%)\end{array}$ & $\begin{array}{c}\text { LAP } \\
\text { n } \\
(\%)\end{array}$ & $\begin{array}{c}\text { Cavity } \\
\text { n } \\
(\%)\end{array}$ & $\begin{array}{c}\text { Ectasia } \\
\text { n } \\
(\%)\end{array}$ \\
\hline $\begin{array}{c}\text { Ever- } \\
\text { smoker } \\
(n=17)\end{array}$ & $\begin{array}{c}11 \\
(64.7)\end{array}$ & $\begin{array}{c}3 \\
(17.6)\end{array}$ & $\begin{array}{c}4 \\
(23.5)\end{array}$ & $\begin{array}{c}5 \\
(29.4)\end{array}$ & $\begin{array}{c}3 \\
(17.6)\end{array}$ & $\begin{array}{c}2 \\
(11.7)\end{array}$ & 0 \\
\hline $\begin{array}{c}\text { Non- } \\
\text { smoker } \\
(n=17)\end{array}$ & $\begin{array}{c}12 \\
(70.5)\end{array}$ & $\begin{array}{c}1 \\
(5.8)\end{array}$ & $\begin{array}{c}7 \\
(41.1)\end{array}$ & $\begin{array}{c}1 \\
(5.8)\end{array}$ & $\begin{array}{c}6 \\
(35.2)\end{array}$ & $\begin{array}{c}1 \\
(5.8)\end{array}$ & $\begin{array}{c}2 \\
(11.7)\end{array}$ \\
\hline
\end{tabular}

Percents of neutrophils, lymphocytes and alveolar macrophages evaluated in the BAL fluid but the level of eosinophils could not be defined. The BAL findings of patients with rheumatoid arthritis were compared with the control group. The number of neutrophils in the control group was found to be significantly higher than that in RA patients $(p=0.01)$, whereas the number of alveolar macrophage cells was higher in RA patients than in controls $(p=0.04)$. Other measurements did not differ significantly between the groups (Table 5). 
Table 5: Comparison of BAL findings between RA patients and controls

\begin{tabular}{cccc}
\hline BAL Findings & RA group (n=34) & Control group(n=5) & p \\
\hline Neutrophil (\%) & $33.84 \pm 20.36$ & $68.95 \pm 13.32$ & $0.01^{*}$ \\
Lymphocyte (\%) & $8.73 \pm 10.84$ & $7.08 \pm 3.22$ & 0.73 \\
CD $/$ CD8 (\%) & $1.98 \pm 2.1$ & $1.52 \pm 0.72$ & 0.64 \\
Alveolar macrophage (\%) & $27.22 \pm 24.73$ & $10.34 \pm 6.87$ & $0.04^{*}$ \\
\hline
\end{tabular}

Alveolar macrophage levels in the BAL fluid of RF- and anti-CCP-positive patients were significantly higher as compared to the seronegative patients $(p=0.02$ and $p=0.01$, respectively). There was no significant difference with regard to the levels of other cells.

No significant difference was found between the BAL findings of smoker and nonsmoker RA patients (Table 6). However, the number of patients with alveolar macrophagedominant BAL fluid was higher among non-smokers than among smokers. On the other hand, the number of patients with neutrophil-dominant BAL fluid was higher in the smoker group (Table 7). 
Table 6: Comparison of BAL findings relative to smoking status

\begin{tabular}{ccc}
\hline BAL findings & Smoker & Non-smoker \\
\hline Neutrophil (\%) & $30.3 \pm 18.5$ & $37.3 \pm 22.06$ \\
Lymphocyte (\%) & $8.2 \pm 13.5$ & $9.2 \pm 7.5$ \\
CD4/CD8 (\%) & $1.8 \pm 2.09$ & $2.1 \pm 2.3$ \\
Alveolar macrophage (\%) & $22.4 \pm 25.0$ & $32.01 \pm 24.2$ \\
\hline
\end{tabular}

Table 7: Cell dominance in BAL fluid relative to smoking status

\section{Smoker Non-smoker}

Neutrophil-dominant

Macrophage-dominant

Lymphocyte-dominant
13

6

2
11

11

3

\section{DISCUSSION}

Our study reveals that there is a correlation between smoking and the markers of disease activity such as RF and anti-CCP in patients with RA. Also, it might be related to early onset of disease and pulmonary involvement in these patients. However, the type of pulmonary involvement, either from a radiographic or inflammatory stand point, seems not to differ with smoking history. 
One of the factors that increase morbidity and mortality of RA is pleuro-pulmonary complications (10). The prevalence of pulmonary involvement in RA varies according to diagnostic methods and has been reported to be $10-80 \%$ (11). Interstitial involvement has been characterized by an abnormality in a single parameter in $56 \%$ of cases. The abnormality is most commonly revealed by the differential cell count of BAL fluid which is followed by HRCT (33\%), PFT (22\%), and chest X-ray (6\%) abnormalities (12). This finding suggests that pulmonary involvement of RA cannot be defined by a single parameter. Therefore, in the present study, it was evaluated using a multi-parameter approach including clinical, functional, radiographic and inflammatory indicators instead of applying a single parameter.

The duration and stage of RA-associated ILD shows a wide variation between individuals. The mean age varies between 57-61 years and the mean duration of disease varies between 123-144 months $(5,9,13)$. In our study, the mean age of patients with pulmonary involvement was 57 years and the mean duration of disease was 138 months. The smokers demonstrated lower mean age and age of onset along with a shorter duration of disease as compared to the non-smokers. This finding suggests that smoking might be associated with early onset of rheumatoid arthritis and might increase the frequency of pulmonary involvement at an earlier stage of the disease.

The close relationship between smoking and RF positivity is a well known fact (1315). Clinically, RF production is increased before the onset of disease in smokers $(16,17)$. Smoking is related with dose-dependent increases in RF and anti-CCP antibody titers in patients with RA (18-20). Genetically, there is a significant relationship between smoking and HLA-shared epitope alleles that determine the risk of seropositive RA (21).

It has also been reported that smoking induces citrullination of some peptides, leads to anti-CCP antibody formation in the presence of epitope sharing and causes development of 
RA $(19,22)$. Several previous reports have failed to show such a link between smoking and anti-CCP levels (23). In our study, both RF and anti-CCP levels of active smokers and exsmokers were found to be significantly higher than those of non-smokers. However there was a decreasing tendency of these markers between active smokers and ex-smokers that might be interpreted as effect of smoking cessation. This finding suggested possible protective effects of smoking cessation in RA patients. Future studies are needed to investigate whether smoking cessation affects the activity of disease and the severity of pulmonary involvement in patients with rheumatoid arthritis.

Pulmonary involvement of RA might be seen as a restrictive or obstructive pulmonary function test defect depending on the predominant site of involvement. In previous studies, the percentage of patients with obstructive and restrictive defect vary between $14-30 \%$ and $10 \%$, respectively $(7,24,25)$. The most frequent pulmonary function test abnormality $(32 \%)$ was restrictive defect in our study population, while obstruction was noted in $6 \%$ of the patients.

It is known that pulmonary nodules are one of the most common radiographic abnormalities in patients with RA, with a rate of $4 \%$ to $37 \%$ in previous studies (26-27). The frequency of nodular appearance in thoracic CT was $68 \%$ in our study. Remmy-Jardin and colleagues observed pulmonary nodules in $22 \%$ and subpleural micronodules and/or pseudoplaque in $17 \%$ of their RA patients, and reported that the number and the size of pulmonary nodules were higher in patients with respiratory symptoms as compared to the asymptomatic ones (5). Inclusion of patients with pulmonary involvement and the relatively small sample size might explain the higher frequency of pulmonary nodules in this study compared to the previous ones. 
Smoking is considered as an important factor in the development of bronchiectasis in patients with RA, with a frequency of $5 \%$ to $30 \%$ in the literature $(28,29)$. It is also believed to be related to respiratory symptoms. However, bronchiectasis is also reported frequently in asymptomatic non-smoker patients (27). In the present study, the frequency of bronchiectasis was $6 \%$ and it did not differ with regard to smoking history.

Development of honeycomb appearance is considered to be the terminal period of interstitial involvement in RA. The frequency of honeycomb development varies depending on disease severity and duration, with a reported frequency of $6-35 \%$ in the literature $(5,12$, 30). We observed relatively lower number of honeycomb appearance which might be associated with the impact of the therapy, since all the included patients were receiving disease-specific treatment.

Bronchoscopy and BAL are not routine evaluation processes in patients with RA. However, they are used in showing inflammatory characteristics of pulmonary involvement and guiding the therapy. Pathological BAL findings are generally found in patients with interstitial involvement (27). Previous clinical trials conducted in patients with asthma and chronic obstructive pulmonary disease (COPD) report a significant relationship between neutrophilic inflammation and smoking history (31). Therefore, neutrophilic inflammation might be expected in RA patients with smoking history. However, Yoshiya et al observed low lymphocyte numbers in smokers with RA, but could not demonstrate significant increase in neutrophil count (32). Our study showed no difference in differential cell counts between smokers and non-smokers. However, the number of patients with neutrophil-dominant alveolitis was higher in the smoking group. In the present study, inclusion of patients receiving treatment for RA may be associated with the BAL fluid findings. 
This study has several limitations. First, it was not possible to compare the BAL fluid findings of smokers and non-smokers with interstitial lung involvement because of the small sample size. If each group had adequate number of patients, it could have been possible to observe the inflammatory difference between smokers and non-smokers. Second, all included patients were receiving treatment. It can be assumed that immune-suppressive therapy may have affected PFT results, BAL findings, and radiographic involvement. However, the lack of difference between the two groups with regard to medications is thought to reduce the impact of treatment on clinical and inflammatory findings. In addition, a prospective follow-up assessment conducted parallel to the ongoing treatment in this patient group may provide valuable information about the effects of smoking on disease progression.

It is suggested that smoking might be associated with markers of disease activity, younger age of onset and pulmonary involvement within shorter disease duration in rheumatoid arthritis. Long-term studies including a higher number of patients are needed to investigate the role of smoking in progression of radiographic and inflammatory findings in pulmonary involvement of RA. 


\section{REFERENCES}

1. Lipsky PE. Rheumatoid arthritis. Fauci AS, Langford CA, Kasper DL, Longo DL, Braunwald E, Hauser SL, Jameson JL (eds). Harrison's Rheumatology 2007: 85-104.

2. KM A, Margaritopoulos G, Economidou F, Siafakas NM. Pivotal clinical dilemmas in collagen vascular diseases associated with interstitial lung involvement. Eur Respir J 2009; 33: 882-96.

3. Baka Z, Buzás E, Nagy G. Rheumatoid arthritis and smoking: putting the pieces together. Arthritis Research \& Therapy 2009; 11: 238.

4. Mayyberry JP, Primack SL, Müller NL. Thoracic manifestations of systemic autoimmune diseases: radiographic and high resolution CT findings. Radiographics 2000; 20: 1623-35.

5. Remy-Jardin M, Remy J, Cortet B, Mauri F, Delcambre B. Lung changes in rheumatoid arthritis: CT findings. Radiology 1994; 193: 375-82.

6. Dawson JK, Fewins HE, Desmond J, Lynch MP, Graham DR. Fibrosing alveolitis in patients with rheumatoid arthritis as assessed by high resolution computed tomography, chest radiography, and pulmonary function tests. Thorax 2001; 56: 6227.

7. Cortet B, Perez T, Roux N, Flipo RM, Duquesnoy B, Delcambre B et al. Pulmonary function tests and HRCT of the lungs in patients with rheumatoid arthritis. Ann Rheum Dis 1997; 56: 596-600.

8. Hunninghake GW, Fauci AS. Pulmonary involvement in the collagen vascular disease. Am Rev Respir Dis 1979; 119: 471-503.

9. Biederer J, Schnabel A, Muhle C, Gross WL, Heller M, Reuter M. Correlation between HRCT findings, pulmonary function tests and bronchoalveolar lavage 
cytology in interstitial lung disease associated with rheumatoid arthritis. Eur Radiol 2004; 14: 272-80.

10. Schwarz MI. Pulmonary manifestations of the collagen vascular diseases. In: Fishman AP, Elias JA, Grippi MA (Eds). Fishman's pulmonary diseases and disorders vol 1, 4 th ed. New York: The McGraw-Hill Co, 2008; 1201-6.

11. Popp W, Ritschka L, Scherak O. Bronchoalveolar lavage in rheumatoid arthritis and secondary Sjogren syndrome. Lung 1990; 168: 221-31.

12. Gabbay E, Tarala R, Will R, Carroll G, Adler B, Cameron D et al. Interstitial lung disease in recent onset rheumatoid arthritis. Am J Respir Crit Care Med 1997; 156: $528-35$.

13. Heliovaara M, Aho K, Aromaa A, Knekt P, Reunanen A. Smoking and risk of rheumatoid arthritis. J Rheumatol 1993; 20: 1830-5.

14. Houssien DA, Scott DL, Jonsson T. Smoking, rheumatoid factors, and rheumatoid arthritis. Ann Rheum Dis 1998; 57: 175-6.

15. Masdottir B, Jonsson T, Manfredsdottir V, Víkingsson A, Brekkan A, Valdimarsson H. Smoking, rheumatoid factor isotypes and severity of rheumatoid arthritis. Rheumatology (Oxford) 2000; 39: 1202-5.

16. Aho K, Heliovaara M, Maatela J, Tuomi T, Palosuo T. Rheumatoid factors antedating clinical rheumatoid arthritis. J Rheumatol 1991; 18: 1282-4.

17. Mattey DL, Dawes PT, Clarke S, Fisher J, Brownfield A, Thomson W et al. Relationship among the HLA-DRB1 shared epitope, smoking, and rheumatoid factor production in rheumatoid arthritis. Arthritis Rheum 2002; 47: 403-7.

18. Klareskog L, Stolt P, Lundberg K, Källberg H, Bengtsson C, Grunewald J et al. A new model for an etiology of rheumatoid arthritis: smoking may trigger HLA-DR 
(shared epitope)-restricted immune reactions to autoantigens modified by citrullination. Arthritis Rheum 2006; 54: 38-46.

19. Mattey DL, Hutchinson D, Dawes PT, Nixon NB, Clarke S, Fisher J et al. Smoking and disease severity in rheumatoid arthritis: association with polymorphism at the glutathione S-transferase M1 locus. Arthritis Rheum 2002; 46: 640-6.

20. Saag KG, Cerhan JR, Kolluri S, Ohashi K, Hunninghake GW, Schwartz DA. Cigarette smoking and rheumatoid arthritis severity. Ann Rheum Dis 1997; 56: 4639.

21. Padyukov L, Silva C, Stolt P, Alfredsson L and Klareskog L. A gene-environment interaction between smoking and shared epitope genes in HLA-DR provides a high risk of seropositive rheumatoid arthritis. Arthritis Rheum 2004; 50: 3085-92.

22. Linn-Rasker SP, van der Helm-van Mil AH, van Gaalen FA, Kloppenburg M, de Vries RR, le Cessie S et al. Smoking is a risk factor for anti-CCP antibodies only in rheumatoid arthritis patients who carry HLA-DRB1 shared epitope alleles. Ann Rheum Dis 2006; 65: 366-71.

23. Finckh A, Dehler S, Costenbader KH, Gabay C. Cigarette smoking and radiographic progression in rheumatoid arthritis. Ann Rheum Dis 2007; 66: 1066-71.

24. Vergnenegre A, Pugnere N, Antonini MT, Arnaud M, Melloni B, Treves R et al. Airway obstruction and rheumatoid arthritis. Eur Respir J 1997; 10: 1072-8.

25. Morrison SC, Mody GM, Benatar SR, Meyers OL. The lungs in rheumatoid arthritisa clinical, radiographic and pulmonary function study. S Afr Med J 1996; 86: 829-33.

26. Zrour SH, Mongi T, Bejia I, Golli M, Rouatbi N, Sakly N et al. Correlations between high resolution computed tomography of the chest and clinical function in patients with rheumatoid arthritis. Joint Bone Spine 2005; 72: 41-7. 
27. Cortet B, Flipo RM, Remy Jardin M, Coquerelle P, Duquesnoy B, Rêmy J et al. Use of high resolution computed tomography of the lungs patient with rheumatoid arthritis. Ann Rheum Dis 1995; 54: 815-9.

28. Hassan WU, Keamey NP, Holland CD, Kelly CA. High resolution computed tomography of the lung in lifelong non-smoking patients with rheumatoid arthritis. Ann Rheum Dis1995; 54: 308-10.

29. Carotti M, Salaffi F, Manganelli P, Salvolini L, Bichi Secchi E, De Berardinis S. The sub clinical involvement of the lung in rheumatoid arthritis: Evaluation by HRCT. Rheumatismo 2001; 53: 280-8.

30. McDonagh J, Greaves M, Wright AR, Heycock C, Owen JP, Kelly C. High resolution computed tomography of the lungs in patients with rheumatoid arthritis and interstitial lung disease. Br J Rheumatol 1994; 33: 118-22.

31. Basyigit İ., Yildiz F, Ozkara SK, Boyacı H, Ilgazlı A. Inhaled corticosteroid effects both eosinophilic and non-eosinophilic inflammation in asthmatic patients. Mediators of Inflamm 2004; 13: 285-91.

32. Yoshiya N, Toshinori $\mathrm{T}$, Takashi S, Narita J, Moriyama H, Terada $\mathrm{M}$ et al. Inflammatory cells in lung disease associated with rheumatoid arthritis. Inter Med 2009; 48: 1209-17. 